\title{
MYXOMA OF RIGHT FEMORAL VEIN ORIGIN PRESENTING AS A RIGHT ATRIAL MASS WITH SYNCOPE
}

Paul S. Ramphal, DM, FRCS(Edin), ${ }^{a}$ Howard W. Spencer, FRCS(Edin), FACS, ${ }^{a}$ Derek I. G. Mitchell, MBBS, DM, and

Charles Denbow, DM, FRCP, FACP, FACC, ${ }^{\text {b }}$ Kingston, Jamaica, West Indies

Myxomas are the most common cardiac tumors, accounting for approximately $50 \%$ of such neoplasms. Right-sided tumors are considerably less common than left-sided tumors ( $20 \%$ vs $80 \%$ ), and myxomas of extracardiac origin presenting as intracardiac masses are rare..$^{1-3} \mathrm{~A}$ case of myxoma originating in a previously undescribed site and presenting as a right atrial mass with syncope is reported.

Clinical summary. A 44-year-old woman was admitted to the University Hospital of the West Indies in January 1993. She had been having progressive dyspnea and episodic syncope over the preceding year. There were no other symptoms. Other medical problems included maturity-onset diabetes mellitus controlled with oral hypoglycemic drugs and hypertension controlled with propranolol $40 \mathrm{mg}$ daily. Physical examination revealed an obese woman with a blood pressure of 140/80 mm $\mathrm{Hg}$, a pulse rate of 90 beats/min and a grade $3 / 6$ systolic murmur at the left sternal edge. The liver was palpable $2 \mathrm{~cm}$ below the right costal margin. Results of liver function tests were

From the Departments of Surgery, Radiology, Anaesthesia, and Intensive Care ${ }^{\mathrm{a}}$ and the Department of Medicine, ${ }^{\mathrm{b}}$ University Hospital of the West Indies, Jamaica, West Indies.

Received for publication March 20, 1998; accepted for publication May 13, 1998.

Address for reprints: Paul S. Ramphal, DM, FRCS(Edin), c/o Departments of Surgery, Radiology, Anaesthesia, and Intensive Care, University Hospital of the West Indies, Mona, Kingston 7, Jamaica, West Indies.

J Thorac Cardiovasc Surg 1998;116:655-6

Copyright $\odot 1998$ by Mosby, Inc.

0022-5223/98 \$5.00+ $0 \quad \mathbf{1 2 / 5 4 / 9 1 6 3 4}$ within normal limits. Chest radiography showed no abnormalities, and electrocardiography revealed sinus tachycardia. Echocardiography showed that the right atrium was almost completely filled by a mobile, homogeneous mass that intermittently occluded the tricuspid orifice and appeared to originate from the area of the eustachian valve. The diagnosis of a right atrial myxoma was made and the patient was taken to the operating theater.

At median sternotomy, bicaval cannulation could not be safely accomplished because palpation of the inferior vena cava (IVC) revealed that the tumor was emerging into the right atrium (RA) from within that vessel. The right femoral vein, superior vena cava, and aortic root were cannulated. On bypass, the right atrium was opened and a club-shaped, glistening, pink mass of firm consistency was noted to be filling it. The mass was not attached to the RA and in fact represented the end of a solid cord of tumor that was emerging from the IVC orifice, and, under tension, could be made to stretch a further $2 \mathrm{~cm}$ into the RA. The point of origin could not be ascertained and the decision was made to amputate the stalk of the tumor under cephalad traction, whereupon the stump, which was approximately $1 \mathrm{~cm}$ in diameter, retracted beyond sight into the IVC. The patient was weaned off bypass uneventfully and her postoperative course was unremarkable.

Pathologic examination of the mass revealed a $3 \times 7-\mathrm{cm}$ firm, smooth tumor. Histologic examination revealed myxoma, with no features of malignancy.

The patient was kept under close supervision with serial ultrasound examinations over the next several months, because recurrence was expected. Examination 6 months after the operation suggested that the site of origin of the tumor was 


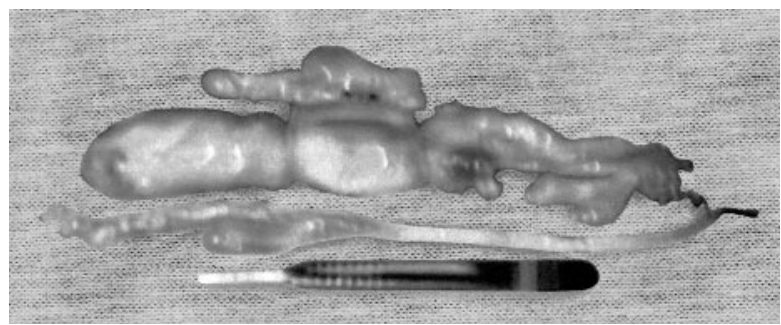

Fig 1. The tumor after excision. The larger end presented as a right atrial mass. The tumor has been folded back on itself to fit into the photograph. (Computer enhanced.)

the area of the anterior IVC wall immediately caudal to the ostia of the hepatic veins. The patient was now dyspneic and the tumor had again entered the right atrium. She was taken to the operating theater and underwent reoperation via median sternotomy and laparotomy. Bypass was instituted and right atriotomy revealed the tumor presenting as a club-shaped mass. The diameter of the intracardiac end of the tumor was several centimeters larger than the IVC. The infrahepatic vena cava was mobilized. The tumor stalk was palpable within the IVC and a cavotomy at the site where the tumor was nearly impalpable was made, approximately half way between the hepatic and renal veins. The tumor consisted of a main stalk and several smaller frondlike structures floating parallel to it, originating at a more caudal point within the cava. After further dissection it became apparent that the origin of the tumor was caudal to the right common iliac vein. The tumor stalks were divided under cephalad tension and allowed to retract into the right common iliac vein. The operative specimen was photographed at the time of excision (Fig 1).

Three months after her second cardiac procedure the patient underwent lower limb venography to try to identify the origin of the tumor. The study suggested that the origin was in the right femoral vein (Fig 2). Venous Doppler ultrasonography did not provide any additional information. The patient declined to undergo any further investigations and did not wish to have any additional surgical procedures, despite being warned that the tumor might recur. At follow-up 4 years later, she remains well, with no ultrasonographic evidence that the tumor has returned to its former size.

Discussion. Myxomas presenting as right atrial masses with extracardiac origin are rare. A literature search reveals only three previously reported cases of a nature similar to ours, with all such myxomas arising from the intrapericardial or suprahepatic IVC or from the eustachian valve. ${ }^{1,3,4}$ This patient may be the only known case of a myxoma arising from a peripheral vein (right femoral vein) and presenting as a right atrial mass. The lack of symptoms other than dyspnea and episodic syncope and the paucity of clinical features of IVC, hepatic venous, or portal venous obstruction in this case is remarkable, given the size of the tumor in relation to the IVC, and is in contrast to previous reports. ${ }^{1,3}$

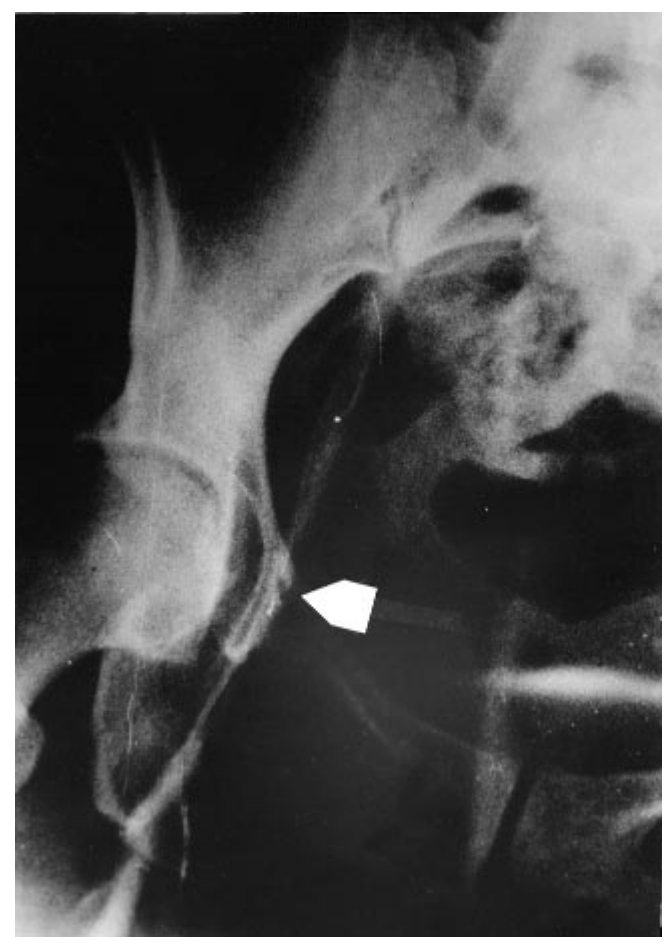

Fig 2. Right femoral venogram. The arrow points to a filling defect in the right femoral vein, believed to represent the point of origin of the tumor.

Precise localization of the point of origin was attempted, because to prevent tumor recurrence the origin must be completely excised, be it free atrial wall, fossa ovalis, eustachian valve, or IVC wall. ${ }^{1-3}$ Ultrasonography and venography have been previously shown to be accurate; however, in the present case, the completely unexpected site of origin did not appear to warrant venography until after the second major procedure.

If the tumor cannot be completely excised, a caval umbrella or similar device should be inserted; this was offered to the patient but was declined. As this case clearly illustrates, rare and bizarre variations of origin of myxomas may occur and will be discovered before the operation only if an index of suspicion is maintained.

\section{REFERENCES}

1. Bortolotti U, Faggian G, Mazzucco A, et al. Right atrial myxoma originating from the inferior vena cava. Ann Thorac Surg 1990;49:1000-2.

2. Chitwood RW Jr. Cardiac neoplasm: current diagnosis, pathology, and therapy. J Card Surg 1988;3:119-54.

3. Cujec B, Ulmer B, Mckaigney JP, Bharadwaj B. Right atrial myxoma presenting as Budd-Chiari syndrome. Ann Thorac Surg 1987;44:658-9.

4. Devig GPM, Clark TA, Aaron BL. Cardiac myxoma arising from the inferior vena cava. Chest 1980;78:784-6. 